Int. J. Dev. Biol. 49: 231-235 (2005)

doi: $10.1387 / \mathrm{ijdb} .041964 \mathrm{hn}$

\title{
Isthmus organizer and regionalization of the mesencephalon and metencephalon
}

\author{
HARUKAZU NAKAMURA* and YUJI WATANABE \\ Department of Molecular Neurobiology, Graduate School of Life Sciences and Institute of Development, Aging and Cancer, Tohoku \\ University, Sendai, Japan
}

\begin{abstract}
The brain vesicles that are formed at an early stage of neural development are the fundamentals of the brain plan. Heterotopic transplantation revealed that the diencephalon could change its fate when juxtaposed to the isthmus (mes-metencephalic boundary), which indicated that the isthmus functions as an organizer for the mesencephalon and metencephalon. Fgf8 is identified as an isthmus organizing signal. Misexpression of Fgf8a and Fgf8b indicated that a strong Fgf8 signal organizes cerebellar development. The transcription factors define the fate of the region. Overlapping expression of Otx2, En1 and Pax2 may define the mesencephalic region and additional expression of $\mathrm{Pax} 3 / 7$ may instruct the mesencephalic region to differentiate into the tectum. The di-mesencephalic boundary is determined by repressive interaction between Pax6 and En1/Pax2 and the mes-metencephalic boundary is defined by repressive interaction between Otx2 and Gbx2. Fgf8 is induced at the border of the Otx2 and Gbx2 expression domain, overlapping with Gbx2 expression.
\end{abstract}

KEY WORDS: isthmus, organizer, tectum, cerebellum, electroporation

\section{Introduction}

The fundamental design of vertebrate brain architecture is formed at the early stage of development as brain vesicles. Primary brain vesicles such as prosencephalon, mesencephalon and metencephalon become subdivided into secondary brain vesicles; telencephalon, diencephalon, mesencephalon, metencephalon and myelencephalon (Fig. 1). Here we will focus on diencephalon, mesencephalon and metencephalon. Diencephalon differentiates into the thalamus, hypothalamus, pretectum and retina etc. Alar plate of the mesencephalon of the lower vertebrates differentiates into the optic tectum, which functions as a visual center and the basal plate differentiates into the tegmentum. The cerebellum differentiates at the dorsal part of the metencephalon and the pons differentiates at the ventral part of the metencephalon. Each region of the brain is characterized by its specific architecture and the mode of cytoarchitectonic development is different from each other.

\section{Organizing activity of the mes-metencephalic boundary} (isthmus)

It was of great interest to find out whether the fate of the brain vesicles are determined from the first moment in developent or not.
To answer this question, ectopic transplantation of the brain vesicles was carried out (Alvarado-Mallart and Sotelo, 1984; Nakamura et al., 1986, 1988). In order to trace the fate of the transplant, interspecific transplantation between quail and chick embryos were adopted. Quail and chick cells could be easily distinguished because of the difference in nuclear structure (Le Douarin, 1973). When presumptive quail mesencephalon was transplanted in the diencephalon or in the metencephalon of chick embryos, it retained its original fate and differentiated into the optic tectum (Alvarado-Mallart and Sotelo, 1984; Nakamura, 1990). Presumptive metencephalon also retained its original fate and differentiated as cerebellum, when transplanted into the mesencephalon or the prosencephalon (Nakamura, 1986, 1990).

Diencephalon could change its fate and differentiate into the tectum when heterotopically transplanted into the mesencephalon. Fate change occurred only when the diencephalon was transplanted in the posterior part of the mesencephalon and completely integrated into the host. In the anterior part of the mesencephalon, the transplanted presumptive diencephalon did not change its original fate even when the transplant was completely integrated into the host. In the mesencephalon, En2 is expressed in a gradient, caudal

Abbreviations used in this paper: Fgf, fibroblast growth factor.

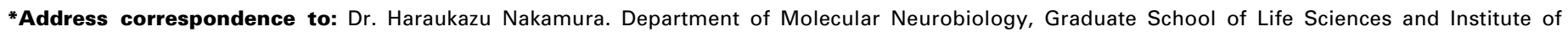
Development, Aging and Cancer, Tohoku University, Seiryo-machi 4-1, Aoba-ku, Sendai 980-8575, Japan. e-mail: nakamura@idac.tohoku.ac.jp
} 

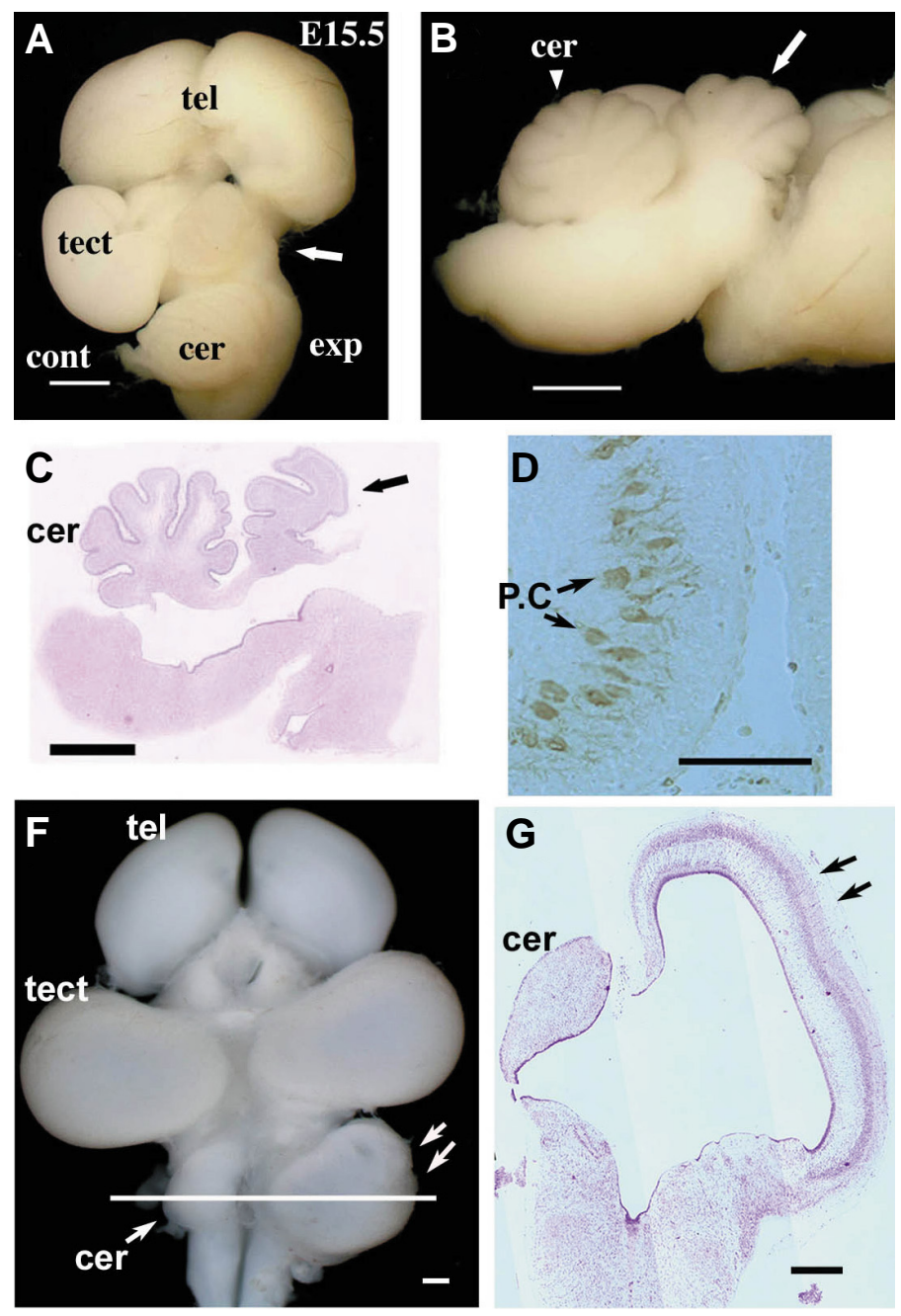

Fig. 1. Fate change of the mesencephalic alar plate to the cerebellum (A-D) and of the metencephalic alar plate to the tectum $(\mathbf{F}, \mathbf{G})$ Misexpression of Fgf8b by in ovo electroporation resulted in a fate change of the mesencephalon to the metencephalon, that is, ectopic cerebellum differentiated in place of the tectum (arrow in A-C). In the cerebellar structure formed in the mesencephalon, external granular layer and Purkinje cells differentiated. Purkinje cell (P.C) differentiation was confirmed by immunostaining with the anti-calbindin antibody, which specifically stains Purkinje cells in the cerebellum (D). Misexpression of Otx2 resulted in a fate change of the metencephalic alar plate to the tectum (double arrows in $G$ and $F$ ). The tectal structure in the metencephalon lacked an external granular layer, but did display a tectal laminar structure (F). The line in (F) indicates the plane of the section of G. Scale bars: (A-C) 4 mm; (D, G) $100 \mu \mathrm{m}$; (F) $200 \mu \mathrm{m}$. Abbreviations: tel, telencephalon; tect, tectum; cer, cerebellum; cont, control side; exp, experimental side. From Sato et al., 2001 and Katahira et al., 2000.

high and rostral low. En2 is not expressed in the diencephalon (Patel et al., 1990). When diencephalon was transplanted near the mes-metencephalic boundary, En2 expression was induced in the transplant (Nakamura and Itasaki, 1992). These results suggested that some factors emanated from the mes-metencephalic boundary. This notion was proven by transplantation of the isthmus to the presumptive diencephalon. The transplanted isthmus could induce tectal structure in the diencephalon (Martinez et al., 1991; BallyCuif et al., 1992; Bally-Cuif and Wassef, 1994).
The organizing molecules were then investigated. Crossley et al., (1996) implanted Fgf8-soaked beads into the diencephalon and showed that Fgf8 could mimic the isthmic activity. Fgf8 induced $E n$ and $W n t 1$ expression in the presumptive diencephalon, which was transformed into the tectum. These results suggested that Fgf8 is the isthmus organizing molecule (Fig. 1). Subsequent gain-of-function studies of Fgf8 in chick and mice and analyses in mutant zebrafish and mice have all suggested that Fgf8 is a signaling molecule emanating from the isthmus (Brand et al., 1996; Crossley et al., 1996; Meyers et al., 1998; Reifers, et al., 1998; Liu etal., 1999; Martinez etal., 1999; Shamim etal., 1999).

It is now accepted that the fate of certain regions is determined by a combination of transcription factors and that the organizing signal changes or stabilizes the expression of the transcription factors. We will discuss how we came to this notion in the following section.

\section{Gene transfer and silencing by in ovo electroporation}

Chick embryos have been important as experimental material because they are easily accessible. But as genetic manipulations such as transgenesis or gene targeting were proved difficult in chick, they became less used in the early 1990s. However Muramatsu et al. (1997) showed that gene transfer could be obtained by in ovo electroporation. We set the precise conditions of electroporation to misexpress a gene of interest in the neural tube of chick embryos (Funahashi et al., 1999; Nakamura et al., 2000; Nakamrua and Funahashi, 2001). This method is so effective that chick embryos were revivified as experimental material for developmental biology. Very recently, disruption of gene expression by inovo electroporation was also obtained(Katahira and Nakamura, 2003). To this end, DNA encoding short hairpin RNA is inserted into the plasmid vector that drives transcription by RNA polymerase III. Electroporation with this expression vector effectively produces small interfering RNA and could disrupt the target RNA. We could then evaluate the effect by in situ hybridization. Production of transgenic chicken by the lentiviral vector (McGrew et al., 2004; Chapman et al., 2005) and sequencing and initial analysis of the chicken genome (International Chicken Genome Sequencing Consortium, 2004; International Chicken Polymorphism Map Consortium, 2004) may increase the importance of the chicken as an experimental model.

\section{Organizing activity of Fgf8}

It was reported that there are at least 8 splicing isoforms of Fgf8 in mice. Differences between isoforms are very subtle, but Fgf8b showed a stronger transformation activity than Fgf8a. Sato et al., showed by RT-PCR that Fgf8a and FgfBb are expressed in the isthmic region, Fgf8b being prevalent (Sato et al., 2001). Then misexpression of Fgf8a and Fgf8b was carried out. Misexpression of Fgf8a in chick by in ovo electroporation or in mice under Wnt1 regulation resulted in fate change of the presumptive diencephalon to the mesencephalon (Lee etal., 1997; Sato etal., 2001). The alar plate of the diencephalon differentiated into the tectum. In the basal plate of the chick embryos, oculomotor nucleus of the mesencephalon extended to the diencephalic region and additional oculomotor nerve trunks came out from the diencephalic region. Misexpression of Fgf8b in chick embryos by in ovo electroporation exerted drastic effects (Fig. 1A-D). Presumptive mesencephalon 


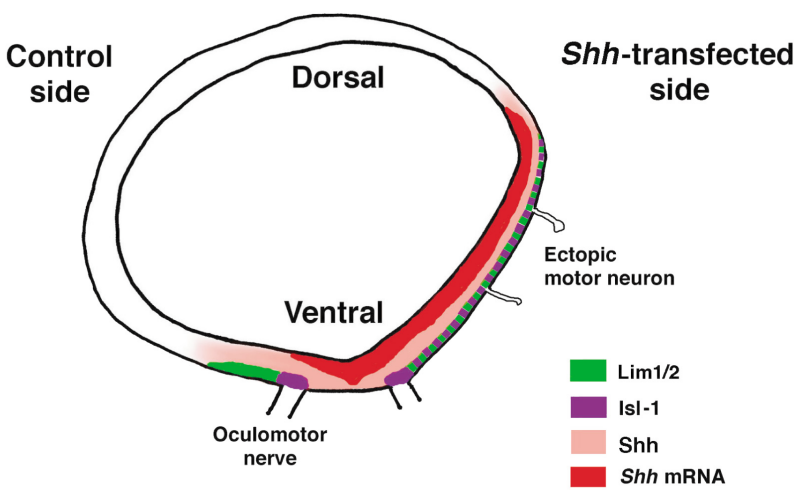

Fig. 2 Shh instructs the mesencephalon to differentiate as ventral tegmentum. After Shh misexpression, the tectal region becomes very small, but the tegmental region expands. Expansion of the tegmentum is suggested by the fact that both Lim 1/2 and Is/-1 positive cells, markers for the ventral region, are induced in the dorsal region. Many motor neuron fibers emerged. From Watanabe and Nakamura, 2000

changed its fate and acquired the characteristics of the metencephalon. Alar plate differentiated as the cerebellum; external granular layer and Purkinje cells differentiated (Fig. 1D). Oculomotor nucleus disappeared and the optic nerve trunk was not formed. These results indicated that presumptive mesencephalon was completely changed to metencephalon (Sato et al., 2001). Fgf8a did not affect the expression of Otx2, Gbx2 and Irx2. In normal embryos, Otx2 is expressed in the prosencephalon and mesencephalon down to the mes-metencephalic boundary. Gbx2 is expressed in the metencephalic region and abuts on Otx2 expression at the mes-metencephalic boundary. Irx2 is also expressed in the metencephalic region.
On the other hand, Fgf8b repressed Otx2 expression and Gbx2 and Irx2 expression extended rostrally up to the presumptive diencephalic region. Thus the region where Gbx2 and Irx2 expression is induced may have changed its fate to differentiate into the cerebellum. En2 was so sensitive to Fgf8 and was induced in the diencephalon by either Fgf8a or Fgf8b, which may explain the transformation of the presumptive diencephalon to the mesencephalon. Transgeneic mice in which Fgf8b is misexpressed under Wnt1 regulation exerted similar effects on downstream gene expression (Liu et al., 1999).

Although the effects of Fgf8a and Fgf8b exert different effects, quantitative experiments indicated that the type difference could be attributable to the difference in strength of the signal. Electroporation with 1/100 concentration of Fgf8b expression vector exerted Fgf8a type effects (Sato et al., 2001). This result together with that of Fgf8b-bead implantation into the diencephalon, in which cerebellar structure differentiated in the center and tectum differentiated in the periphery, suggests that the region which is exposed to strong Fgf8 signal may differentiate into the cerebellum and the region where Fgf8 signal is weak may differentiate into the tectum. Indeed in normal development, Fgf8 mRNA is expressed in the region of the presumptive cerebellum. Strong Fgf8 signal activates the Ras-ERK signaling pathway to organize cerebellar differentiation (Sato and Nakamura, 2004; Matsumoto etal., 2004), but precise regulation of the signal by the antagonistic regulator Sprouty2 is needed (Suzuki-Hirano et al., 2005).

\section{Di-mesencephalic and mes-metencephalic boundary formation}

The regional property may be determined by the combination of transcription factors. Otx2 is expressed in the prosencephalon and mesencephalon and Gbx2 is expressed in the metencephalic
Fig. 3. Schematic drawing of the brain vesicles defining mesencephalon and metencephalon. The fundamental brain plan comprises three primary brain vesicles. These vesicles, prosencephalon (pros), mesencephalon (mes) and rhombencephalon (rhomb), subdivide into secondary brain vesicles; telencephalon (tel), diencephalon (di), mesencephalon (mes), metencephalon (met) and myelencephalon (myel). The fate of the region is determined by a combination of the transcription factors. The anterior tip of the prosencephalon and the mesmetencephalic boundary function as organizers. Organizing signal changes or stabilizes the expression of transcription factors, thus the organizer affects the fate of the adjacent region. Overlapping expression of Otx2, Pax2 and En 1 defines the mesencephalon and additional expression of Pax3/7 ensures tectum differentiation (Matsunaga et al., 2001). Di-mesencephalic boundary are determined by repressive interaction between Pax6 and En1/Pax2. Mes-metencephalic boundary is determined by repressive interaction of Otx2 and Gbx2. A strong Fgf8 signal in the mesencephalon represses Otx2 expression and induces Gbx2 expression and changes the fate of the mesencephalon to the metencephalon. In normal development, cerebellum differentiates into the metencephalon, which may be exposed to strong Fgfo signal because Fgf8mRNA localizes in the metencephalon.

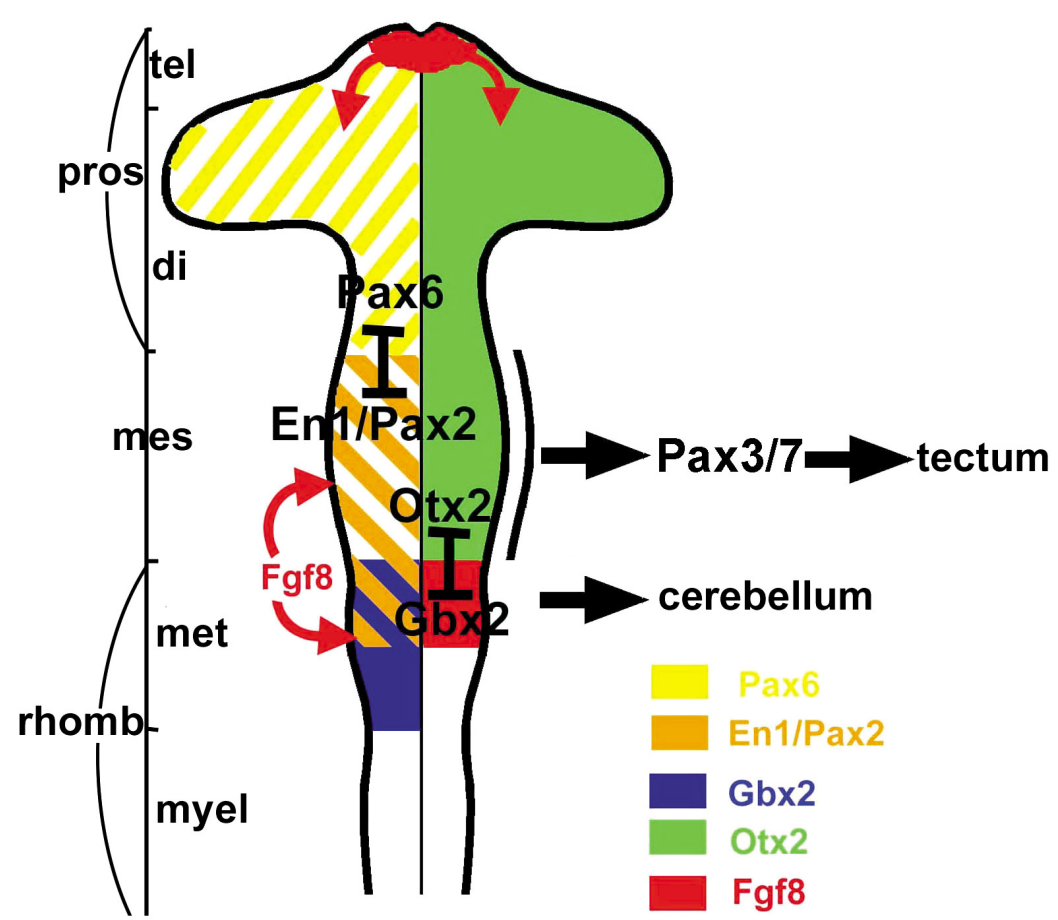


region from the early stage of development. In early stages, their expression is overlapping around the boundary, but abuts at the mes-metencephalic boundary around the 10-somite stage. Targeted disruption of Otx2 in mice reulsts in deletion of the prosencephalic, metencephalic and the anterior rhombencephalic region (Acampora et al., 1995; Ang et al., 1996; Matsuo et al., 1995). On the other hand, Gbx2-knock out mice have abnormalities in the isthmus and caudal extension of the mesencephalon (Wasserman et al., 1997).

Misexpression of Otx2 and Gbx2 was carried out in mice and chick (Brocolli et al., 1999; Millet et al., 1999; Katahira et al., 2000). Mesencephalic superior colliculus in mice or optic tectum in chick differentiated in place of the cerebellum after misexpression of Otx2 (Fig. 1F,G). On the other hand, the posterior limit of the optic tectum shifted anteriorly after misexpression of Gbx2. Otx2 and Gbx2 repressed each other's expression in both mice and chick and Fgf8 expression was induced at the interface of the Otx2 and Gbx2 expression domain, overlapping with Gbx2 expression. The results indicated that mes-metencephalic boundary is set by a repressive interaction between Otx2 and Gbx2 (Fig. 3).

For the induction and maintenance of Fgf8 expression, Wnt1Limx1b system may be involved. Limx1b could induce Wnt1 expression (Adams et al., 2000; Matsunaga et al., 2002), in turn Wnt1 could induce Fgf8 expression (Matsunaga et al., 2001). On the other hand, Limx1b repressed Fgf8 expression in a cell autonomous manner but induced Fgf8 expression in the neighboring cell (Matsunaga et al., 2002). This gene expression network will provide clear abutting of Otx2 and Gbx2 expression and results in induction and maintenance of Fgf8 expression at the border of Otx2 and Gbx2 expression domain.

Pax6 is expressed in the prosencephalon. En1 and Pax2 first covers the whole mesencephalon, but later the expression is limited to the isthmic region. Misexpression of Pax6 resulted in posterior shift of the di-mesencephalic boundary. Posterior commissure is formed in the pretectum, which is a part of diencephalon and is a good landmark of di-mesencephalic boundary. The posterior commissure became wider and extended more caudally after misexpression of Pax6. Pax6 repressed Pax2 and En1 expression (Fig. 3).

On the other hand, En1 or En2 repressed Pax 6 expression and induced Fgf8 expression in the diencephalon. Consequently, ectopic tectum differentiated in the diencephalon. Thus, it was suggested that di-mesencephalic boundary is formed by repressive interaction between Pax6 and En1/Pax2 (Matsunaga etal., 2000).

\section{Regionalization along the dorsoventral axis}

The Sonic hedgehog (Shh) molecule is expressed in the floor plate of the neural tube up to the diencephalon. Shh is necessary for the neural cells to acquire a ventral property for instance to become motor neurons (Tanabe and Jessell, 1996). In the mesencephalon, alar plate differentiates into the optic tectum and the basal plate differentiates into the tegmentum.

Misexpression of Shh in a wide region of the mesencephalon by in ovo electroporation resulted in expansion of the tegmental region dorsally and a very small tectum fused with the other (non transfected) side of the tectum (Fig. 2). The tectum related genes, En1, En2, Pax2, Pax5 and Fgf8 expressions were repressed by
Shh (Watanabe and Nakamura, 2000). Pax7, a marker gene for the tectum, was also repressed by Shh. Otx2 expression was indifferent to Shh. On the other hand, ventral markers, such as HNF3 $\beta$ and ptc expression were induced. Ventral cell types were also induced by Shh. Isl-1 and Lim1/2 expression region both extended dorsally. Immunohistochemical staining with SC1 antibody specific for motor neurons showed that the region of motor neurons also expanded dorsally and that many ectopic motor neuron fibers emerged from the dorsolateral midbrain. Region of the dopamine neurons and serotonergic neurons also extended dorsally.

In conclusion, Shh ventralizes the mesencephalon. A strong Shh signal may force the mesencephalic cells to differentiate into the tegmentum and a weak signal or another signal emanating from the tegmentum may confer the ventral characteristics to the tectal cells.

\section{Perspectives}

All these results indicate that a strong FGF8 signal organizes cerebellar development. Our preliminary study indicate that a strong Fgf8 signal activates the Ras-ERK signaling pathway (Sato et al., unpublished data). This pathway may not be crucial for tectal development. It will be of great interest to determine which signaling pathway has to be activated for the differentiation of the tectum to proceed.

\section{References}

ACAMPORA,D., MAZAN, S., LALLEMAND, Y., AVANTAGGIATO, V., MAURY, M., SIMEONE, A. and BRULET, P. (1995). Forebrain and midbrain regions are deleted in Otx2-/-mutants due to a defective anterior neuroectoderm specification during gastrulation. Development 121: 3279-3290.

ADAMS, K. A., MAIDA, J. M., GOLDEN, J. A. and RIDDLE, R.D. (2000). The transcriptional factor Lmx1b maintains Wnt1 expression within the isthmic organizer. Development 127:1857-1867.

ALVARADO-MALLART R.M. and SOTELO,C. (1984). Homotopic and heterotopic transplantations of quail tectal primordia in chick embryos: organization of the retinotectal projections in the chimeric embryos. Dev. Biol. 103:378-398.

ANG, S.-L., JIN, O., RHINN, M., DAIGLE, N., STEVENSON, L. and ROSSANT, J. (1996). A targeted mouse Otx2 mutation leads to severe defects in gastrulation and formation of axial mesoderm and to deletion of rostral brain. Development 122: 243-252.

BALLY-CUIF, L., ALVARADO-MALLART, R.M., DARNELL, D.K. and WASSEF, M. (1992). Relationship between Wnt-1 and En-2 expression domains during early development of normal and ectopic met-mesencephalon. Development 115: 999-1009.

BALLY-CUIF, L. and WASSEF, M. (1994). Ectopic induction and reorganization of Wnt-1 expression in quail/chick chimeras. Development 120: 3379-3394.

BROCCOLI, V., BONCINELLI, E. and WURST, W. (1999). The caudal limit of Otx2 expression positions the isthmic organizer. Nature 401: 164-168.

CROSSLEY, P.H., MARTINEZ, S. and MARTIN, G.R. (1996). Midbrain development induced by FGF8 in the chick embryo. Nature 380: 66-68.

FUNAHASHI, J., OKAFUJI, T., OHUCHI, H., NOJI, S., TANAKA, H. and NAKAMURA, $H$. (1999). Role of Pax5 in the regulation of a mid-hindbrain organizer's activity. Dev. Growth Differ. 41: 59-72.

INTERNATIONAL CHICKEN GENOME SEQUENCING CONSORTIUM (2004). Sequence and comparative analysis of the chicken genome provide unique perspectives on vertebrate evolution. Nature 432: 695-716.

INTERNATIONAL CHICKEN POLYMORPHISM MAP CONSORTIUM (2004). A genetic variation map for chicken with 2.8 million single-nucleotide polymorphisms. Nature 432: 717-722. 
ITASAKI, N. and NAKAMURA, H. (1992). Rostrocaudal polarity of the tectum in birds: correlation of en gradient and topographic order in retinotectal projection. Neuron 8: 787-798.

KATAHIRA, T., SATO, T., SUGIYAMA, S., OKAFUJI, T., ARAKI, I., FUNAHASHI, J. and NAKAMURA, H. (2000). Interaction between Otx2 and Gbx2 defines the organizing center for the optic tectum. Mech. Dev. 91:43-52.

KATAHIRA, T. and NAKAMURA, H. (2003). Gene silencing in chick embryos with vector-based small interfering RNA system. Dev. Growth Differ. 45: 361-367.

LE DOUARIN, N. (1973). A biological cell labeling technique and its use in experimental embryology. Dev. Biol. 30: 217-222.

LEE, S. M. K., DANIELIAN, P. S., FRITZSCH, B. and MCMAHON, A. P. (1997). Evidence that FGF8 signalling from the midbrain-hindbrain junction regulates growth and polarity in the developing midbrain. Development 124: 959-969.

LIU, A., LOSOS,K. and JOYNER, A.L. (1999). FGF8 can activate Gbx2 and transform regions of the rostral mouse brain into a hindbrain fate. Development 126: 4827-4838.

MARTINEZ, S., WASSEF, M. and ALVARADO-MALLART, R.M. (1991). Induction of a mesencephalic phenotype in the 2-day-old chick prosencephalon is preceded by the early expression of the homeobox gene en. Neuron 6:971-981.

MATSUMOTO, K., NISHIHARA, S., KAMIMURA, M., SHIRAISHI, T., OTOGURO, T., UEHARA, M., MAEDA, Y., OGURA, K., LUMSDEN, A. and OGURA, T. (2004) The prepattern transcription factor Irx2, a target of the FGF8/MAP kinase cascade, is involved in cerebellum formation. Nat. Neurosci. 7: 605-612.

MATSUNAGA, E., ARAKI, I. and NAKAMURA, H. (2000). Pax6 defines the dimesencephalic boundary by repressing En1 and Pax2. Development 127: 2357-2365.

MATSUNAGA, E., ARAKI, I. and NAKAMURA, H. (2001). Role of Pax3/7 in tectum regionalization. Development 128: 4069-4077.

MARTINEZ, S., CROSSLEY, P.H., COBOS, I., RUBENSTEIN, J.L. and MARTIN, G.R. (1999). FGF8 induces formation of an ectopic isthmic organizer and isthmocerebellar development via a repressive effect on Otx2 expression. Development 126: 1189-1200.

MATSUNAGA, E., KATAHIRA, T. and NAKAMURA,H. (2002). Role of Lmx1b and Wnt1 in mesencephalon and metencephalon development. Development 129: 5269-5277.

MATSUO, I., KURATANI, S., KIMURA, C., TAKEDA, N. and AIZAWA, S. (1995). Mouse Otx2 functions in the formation and patterning of rostral head. Genes Dev. 9: 2646-2658.

MEYERS, E. N., LEWANDOSKI, M. and MARTIN, G.R. (1998). An Fgf8 mutant allelic series generated by Cre- and Flp-meddiated recombination. Nature Genet. 18:136-141.

MILLET, S., CAMPBELL, K., EPSTEIN, D.J., LOSOS, K., HARRIS, E. and JOYNER, A.L. (1999). A role for $G b \times 2$ in repression of Otx2 and positioning the mid/ hindbrain organizer. Nature 401:161-164.
MURAMATSU, T., MIZUTANI, Y., OHMORI, Y. and OKUMURA, J. (1997) Comparison of three nonviral transfection methods for foreign gene expression in early chicken embryos in ovo. Biochem. Biophys. Res. Comm. 230: 376380 .

NAKAMURA, H. (1990). Do CNS anlagen have plasticity in differentiation? Analysis in quail-chick-chimera. Brain Res. 511: 122-128.

NAKAMURA, H. and FUNAHASHI, J. (2001). Introduction of DNA into chick embryos by in ovo electroporation. Methods 24: 43-48.

NAKAMURA, H., NAKANO, K. E., IGAWA, H.H., TAKAGI, S. and FUJISAWA, H. (1986). Plasticity and rigidity of differentiation of brain vesicles studied in quailchick chimeras. Cell Differ. 19:187-193.

NAKAMURA, H., TAKAGI, S., TSUJI, T., MATSUI, K. A. and FUJISAWA, H. (1988) The Prosencephalon has the capacaity to differentiate into the optic tectum: Analysis by chick-specific monoclonal antibodies in quail-chick-chimeric brains. Dev. Growth Differ. 30:717-725.

NAKAMURA, H., WATANABE, Y. and FUNAHASHI, J. (2000). Misexpression of genes in brain vesicles by in ovo electroporation. Dev. Growth Differ. 42: 199201.

PATEL, N. H., MARTIN-BlANCO, E., COLEMAN, K. G., POOLE, S. J., ELLIS, M. C., KORNBERG, T. B. and GOODMAN, C. S. (1989). Expression of engrailed proteins in arthropods, annelids and chordates. Cel/ 58: 955-968.

REIFERS, F., BÖHLI, H., WALSH, E. C., CROSSLEY, P. H., STAINIER, D. Y. R. and BRAND, M. (1998). Fgf8 is mutated in zebrafish acerebellar (ace) mutants and is required for maintenance of midbrain-hindbrain boundary development and somitogenesis. Development 125: 2381-2395.

SATO, T., ARAKI, I. and NAKAMURA, H. (2001) Inductive signal and tissue responsiveness to define the tectum and the cerebellum. Development 128: 2461-2469.

SATO, T. and NAKAMURA, H. (2004) The Fgf8 signal causes cerebellar differentiation by activating the Ras-ERK signaling pathway. Development 131 : 4275-7285

SHAMIM, H., MAHMOOD, R., LOGAN, C., DOHERTY, P., LUMSDEN, A. and MASON, I. (1999). Sequential roles for Fgf4, En1 and Fgf8 in specification and regionalisation of the midbrain. Development 126: 945-959.

SUZUKI-HIRANO, A., SATO, T. and NAKAMURA, H. (2005). Regulation of isthmic Fgf8 signal by Sprouty2. Development 132: 257-265.

TANABE, Y. and JESSELL, T. M. (1996). Diversity and pattern in the developing spinal cord. Science 274: 1115-1123.

WASSARMAN, K. M., LEWANDOSKI, M., CAMPBELL, K., JOYNER, A. L., RUBENSTEIN, J. L. R., MARTINEZ, S. and MARTIN, G. R. (1997). Specification of the anterior hindbrain and establishment of a normal mid/hindbrain organizer is dependent on Gbx2 gene function. Development 124: 2923-2934.

WATANABE, Y. and NAKAMURA, H. (2000). Control of chick tectum territory along dorsoventral axis by sonic hedgehog. Development 127: 1131-1140. 